\title{
A IMPORTÂNCIA DE ATIVIDADES LÚDICAS COM CRIANÇAS ONCOLÓGICAS: Relato de Experiência
}

Gilmara Beserra de OLIVEIRA ${ }^{1}$

Itacira PEDROSA ${ }^{1}$

Lericiana SANTANA ${ }^{1}$

Polianna ALVES 1

Thaisy SARMENTO²

${ }^{1}$ Discentes do $10^{\circ}$ Período do Curso de Bacharelado em Enfermagem da Universidade Federal de Campina Grande Centro de Educação e Saúde.

${ }^{2}$ Docente do Curso de Bacharelado em Enfermagem da Universidade Federal de Campina Grande - Centro de Educação e Saúde. Email: thaisysarmento@hotmail.com

Recebido em: 19/02/2014 - Aprovado em: 30/06/2014 - Disponibilizado em: 30/07/2014

\section{RESUMO}

Objetivo: Relatar a vivência de acadêmicas de enfermagem no setor de oncopediatria, ressaltando a importância de atividades lúdicas com crianças hospitalizadas. Percurso Metodológico: Trata-se de um estudo descritivo do tipo relato de experiência, realizado em um hospital universitário, por meio das estudantes do $10^{\circ}$ período de enfermagem durante a disciplina de estágio supervisionado II. Resultados e Discussão: A experiência se deu no setor da oncopediatria do Hospital Alcides Carneiro em Campina Grande - PB, no qual foram realizadas atividades lúdicas com as crianças hospitalizadas, para que estas adquirissem uma maior confiança nos profissionais e consequentemente uma melhor resposta ao tratamento. Considerações Finais: Percebemos que existem problemas estruturais no referido hospital para que as realizações destas atividades sejam mais apropriadas, porém estes não podem atrapalhar estas realizações, pois observamos que as respostas das crianças frente a essas ações melhoram o quadro clínico, ajudando durante o tratamento e especialmente a qualidade de vida destas crianças. Tornando a hospitalização menos traumática.

Palavras chave: Câncer. Oncologia pediátrica. Hospitalização. Brinquedoteca. Atividade lúdica.

\section{ABSTRACT}

Objective: To report the experience of nursing students in pediatric oncology sector, highlighting the importance of play activities with hospitalized children. Course Methodology : This is a descriptive study of the experience report , conducted in a university hospital, by the students of the 10th period of nursing during the course of supervised type II . Results and Discussion : The experiment took place in the Hospital 's pediatric oncology Alcides Carneiro sector in Campina Grande - PB , where recreational activities were conducted with hospitalized children , so that they acquire an increased reliance on professionals and consequently a better response to treatment . Final Thoughts : We realize that there are structural problems in the hospital so that the achievements of these activities are most appropriate , but these can not hinder these achievements, because we observed that children's responses against these actions improve the clinical picture, helping during treatment and especially the quality of life of these children . Making less traumatic hospitalization.

Keywords : Cancer . Pediatric oncology . Hospitalization. Playroom . Playful activity .

\section{INTRODUÇÃO}

O câncer infantil era classificado como

uma doença aguda e de evolução inegavelmente fatal, sendo uma das principais causas de morte infantil no Brasil. Nos dias de hoje tem sido visto como uma doença crônica

e com expetativa de cura na maioria dos 
casos. Cânceres infantis podem ser 2/3 curáveis se o diagnóstico for precoce e preciso e se a terapêutica instituída for adequada (CAGNIN et al. 2004).

No qual, o local de tratamento é de extrema importância, pois crianças estabelecem um vínculo e uma intimidade maior com ambiente hospitalar devido às internações recorrentes e ao tempo de duração destas. Fazendo com que os profissionais que atuam nos serviços desenvolvam vínculos e conheçam particularidades tanto da família quanto da criança, aprendendo a identificar as suas necessidades para, assim, prestarem um cuidado com qualidade (AVANCI, et al. 2009)

Portanto adoecer é um evento inesperado e estressante, a criança com câncer pode desenvolver sequelas físicas e psíquicas marcantes para sua vida. Além disso, a mudança de rotina, ocasionada pela doença, limita a criança a praticar atividades inerentes da infância (CARDOSO, 2007).

Além de lidar com o diagnóstico, começa a surgir outros fatores a serem enfrentados pela criança, como a incerteza em relação ao futuro, perda de controle, dependência, perda de privacidade, limitação das suas atividades, mudança de rotina, dentre outros. Para a enfermagem e todos os profissionais de saúde conseguir lidar com os problemas referentes ao quadro clínico da doença é importante conhecer os aspectos biológicos, psicológicos e sociais (CARDOSO, 2007).

De acordo com o autor supracitado todos os sintomas físicos ocasionados pelo tratamento representam uma ameaça à autoimagem da criança e a imagem que os outros têm dela, provocando reações emocionais como ansiedade, raiva, culpa ou depressão. Assim como também no que se refere aos aspectos comportamentais, a criança poderá isolar-se, ter uma diminuição no rendimento escolar, e até mesmo não desejar mais frequentar a escola.

Pedreira e Palanca (2007) relata sobre as particularidades que envolvem o tratamento da criança com câncer e seus aspectos psicossociais, como as hospitalizações, procedimentos médicos, efeitos colaterais, acompanhamento em longo prazo, que são eventos estressantes à criança.

Em relação aos aspectos sociais temos as necessidades humanas básicas que são inerentes ao ser humano. Horta (1979) define necessidades humanas básicas como sendo "estado de tensões conscientes ou inconscientes, resultantes dos desequilíbrios hemodinâmicos dos fenômenos vitais". A autora supracitada ainda diz que são condições ou situações que o indivíduo, família e comunidade apresentam decorrentes do desequilíbrio de suas necessidades básicas 
que exijam uma resolução, podendo ser aparentes, verbalizadas ou não, em estado de equilíbrio dinâmico as necessidades não se manifestam, porém estão latentes e surgem com maior ou menos intensidade, dependendo do desequilíbrio instalado.

Uma criança com câncer é um paciente acometido de desequilíbrios orgânicos, portanto emocionalmente fragilizados. Com necessidades especificas particulares, uma vez que seu diagnostico implica a um tratamento hospitalar longo, corroborando para que essa criança vivencie uma experiência negativa. Visto isso uma assistência direcionada a uma atenção continuada e individualizada quanto ao seu aspecto físico e psicológico, este último atrelado à necessidade de segurança, de amor e gregária torne-se fundamental (MOURA, RESCK, DÁZIO, 2012).

De acordo com os autores supracitados uma assistência embasada na humanização se faz necessária no ambiente onde se encontra uma criança com câncer. A enfermagem pode contribuir para torna mais humana a hospitalização deste paciente, desenvolvendo uma relação de empatia, através de atividades lúdicas, possibilitando uma melhor interação enfermeiro/paciente, contribuindo para amenizar a experiência negativa e cedendo espaço para momentos de descontração, relaxamento, alegria, buscando melhorar o seu estado de espírito, ajudando-os a encarar melhor a situação vivenciada e auxiliando-os na sua reabilitação.

Portanto a brinquedoteca em hospitais pode permitir à criança, ao adolescente e aos familiares o conhecimento sobre a doença, durante as atividades é possível favorecer o intercâmbio entre as crianças e os familiares, favorecendo uma troca de experiências, conhecimentos e angústias que surgem diante das doenças e do tratamento. Garantindo assim um atendimento médico humanizado e de qualidade a estas crianças, a brinquedoteca tem se mostrado bastante eficiente, reduzindo o tempo de internação e acelerando o processo de recuperação (SOUZA, MARTINS; 2013).

A exigência de uma brinquedoteca em hospitais que possuam atendimento a crianças internadas é atualmente obrigatória em todo o território nacional, estando amparada pela Lei Federal 11.104 de 21/03/2005. Esta lei surgiu a partir da consciência humanista nos hospitais e a inclusão do brinquedo nesses ambientes, fazendo parte da terapêutica da criança internada (BRASIL, 2005).

(2013) a criança quando internada não consegue se expressar apropriadamente devido à doença o que torna mais difícil o processo de internamento, sendo esta manifestada através do choro e da irritabilidade, dificultando assim o tratamento. 
Portanto o brincar pode contribuir para que se reveja o modelo tradicional de intervenção e cuidado de crianças hospitalizadas. A brincadeira durante a hospitalização proporciona: diversão, relaxamento, diminuição do estresse da separação e angústia, proporcionando uma interação positiva com outras pessoas. Esta brincadeira deve e pode ser empregado na explicação dos procedimentos a serem realizados, facilitando assim a compreensão e o consentimento da criança.

Tendo em vista o exposto, o brincar é importante para a criança, e a equipe profissional deve reconhecer essa necessidade, proporcionando meios para sua realização e incorporá-la ao cuidado diário. A Resolução do Conselho Federal de Enfermagem (COFEN) no 295(18), no artigo $1^{\circ}$, afirma que é competência do enfermeiro atuante na pediatria, a utilização da técnica do brinquedo terapêutico durante a realização do cuidado à criança e família hospitalizadas.

Portanto todos os profissionais de saúde devem se organizar e dedicar parte do tempo para trabalhar com o brinquedo terapêutico e utilizar a brinquedoteca com o intuito de que as crianças melhorem rapidamente. $\mathrm{O}$ trabalho de entretenimento das crianças hospitalizadas demonstra que existem modificações de comportamento nos pacientes que participam de atividades lúdicas nos hospitais. Quando uma criança hospitalizada consegue ter momentos de distração e de divertimento, mergulham em um universo de possibilidades (SOUZA, MARTINS; 2013).

Desta forma este trabalho teve como objetivo relatar a vivência das acadêmicas de enfermagem no setor de oncopediatria, ressaltando a importância de atividades lúdicas durante a hospitalização a fim de construir um ambiente que favoreça a interação das crianças entre si e com os profissionais, tornando o tratamento menos desgastante.

\section{PERCURSO METODOLÓGICO}

Esta analise utiliza o método de estudo descritivo, do tipo relato de experiência, de acordo com Minayo (2007) o relato de experiência deve descrever os fatos e fenômenos de acordo com a realidade permitindo aos autores descrever situações vivenciadas por estes.

Esta pesquisa foi acerca da vivência de quatro acadêmicas de enfermagem da Universidade Federal de Campina Grande UFCG, campus Cuité, no setor de oncopediatria do Hospital Universitário Alcides Carneiro - HUAC, durante a disciplina de estágio supervisionado II, em conjunto com a professora supervisora.

A disciplina estágio supervisionado II trata-se de um estágio curricular, por um semestre, em que o aluno fica inserido em um 
hospital, acompanhado por um docente, para vivenciar a assistência de enfermagem e colocar em prática os conteúdos aprendidos em sala de aula, buscando o desenvolvimento de habilidades técnicas, reflexivas e científicas.

Este estágio ocorreu no período de outubro de 2013 até janeiro de 2014, no Hospital Universitário Alcides Carneiro HUAC, localizado em Campina Grande - PB, na rua Carlos Chagas, s/n, bairro São José.

O Hospital Universitário possui cinco alas (Clínica, pneumologia, endocrinologia, infectologia e cirúrgica), além de Centro Cirúrgico, Pediatria, Oncopediatria, UTI adulto e infantil. Também oferece serviços ambulatoriais, de apoio, diagnóstico e tratamento. Realização de eletrocardiograma, ecocardiograma, sala de troca de sonda vesical, pequenas cirurgias, entre outros.

\section{RESULTADOS E DISCUSSÃO}

Estágio realizado por quatro acadêmicas, durante a disciplina Estágio Supervisionado II, no decorrer do $10^{\circ}$ período do curso de enfermagem, da Universidade Federal de Campina Grande - UFCG, Campus Cuité.

O setor de oncopediatria possui posto de enfermagem em conjunto com a sala de procedimentos, três enfermarias, dez leitos, uma brinquedoteca. A oncopediatria localizase ao lado da pediatria sendo a brinquedoteca dividida para os pacientes oncológicos e os pacientes da pediatria, com outras patologias diversas.

As crianças internadas eram de ambos os sexos, predominando o sexo masculino, com idades entre dois a dezoito anos de idades, com internação maior entre 8 aos 13 anos de idade.

Segundo o Instituto Nacional de Câncer - INCA (2014) há uma diversificação nos indíces dos vários cânceres infantojuvenil, dependendo de cada população. A proporção do câncer infantil em países em desenvolvimento, na qual a parcela populacional infantil chega a $50 \%$, é de $3 \%$ a $10 \%$ do total de neoplasias; nos países desenvolvidos os números diminuem para cerca de $1 \%$. Assim como a incidência, a mortalidade também apresenta padrões variados. Nos paises desenvolvidos o óbito por neoplasia é considerado a segunda causa de morte na infância, o que equivale a cerca de $4 \%$ a $5 \%$, entre criaças de 1 a 14 anos, enquanto nos países em desenvolvimento a taxa de óbito é aproximadamente $1 \%$, pelo fato das doenças infecciosas apresentarem como as principais causas de óbito.

A leucemia é o tipo de câncer mais comum na população infantojuvenil, aproximadamente $25 \%$ a $35 \%$. A incidência dos tumores de sistema nervoso são principalmente em crianças menores de 15 
anos de idade, com predomínio aos 10 anos. Estima-se que cerca de $8 \%$ a $15 \%$ das neoplasias pediátricas estejam representadas por esse grupo, sendo o mais frequente tumor sólido na faixa etária pediátrica (INCA, 2014).

Assim como os dados afirmam a incidência predominante da leucemina na população infantojuvenil, o câncer mais frequente nas crianças internadas no setor de oncopediatria do Hospital Universitário Alcides Carneiro também era a leucemia, tanto linfóide, quanto a mielóide.

Entretanto a hospitalização infantil
traz experiências negativas e, por vezes,
marcantes para os seus principais protagonistas: a criança/adolescente e sua família. $O$ ingresso num ambiente de certa forma estranho; a alteração do cotidiano da criança/adolescente, ou, entre outros, a privação de contacto com os seus amigos, parentes, exigem a mobilização de recursos e estratégias que, por vezes, se encontram reduzidos nesta etapa de vulnerabilidade dos mesmos (CAIRES, et. al., 2013).

Contudo desde a determinação do diagnóstico, as crianças em tratamento do câncer são submetidas a vários procedimentos invasivos. Confiar em pessoas até o momento desconhecidas, ter que adaptar-se aos novos horários, receber vários tipos de medicações, permanecer em quarto ou enfermaria, ser privada de atividades de lazer, são situações que não faziam parte do cotidiano desta criança e que caracterizam assim uma hospitalização (RIBEIRO, 2013).

Os limites encontrados na hospitalização destas crianças no HUAC (Hospital Universitário Alcides Carneiro), em especial as crianças com câncer são inúmeros. Além dos normalmente encontrados em todas as hospitalizações pediátricas, as crianças oncológicas ainda apresentam um isolamento maior, pois muitas vezes sua imunidade é baixa devido ao uso dos quimioterápicos, tornando-as mais isoladas, impedindo que estas interajam com outras crianças ali internadas.

Por vezes as crianças não podem se deslocar a brinquedoteca, esta como já foi mencionado não pertence somente a oncopediatria, tornando o brincar para elas mais difícil, pois a equipe tem que trazer o brinquedo até as enfermarias. Quando em alguns casos elas podem se deslocar até a brinquedoteca as outras crianças, da ala pediátrica, olham com olhar de pena e até mesmo de medo, pois elas têm que ir com máscara e de certa forma são estigmatizadas devido à doença, porque muitos associam o diagnóstico de câncer com a morte.

Esta brinquedoteca, o espaço voltado para atividades recreativas, tinha a participação de profissionais e estagiários que 
desenvolvem as atividades lúdicas. Ocorre que, as crianças do setor oncopediátrico brincavam com restrições neste espaço, pois não tinham acesso a um ambiente preparado para ofertar o brincar e o lúdico de modo íntegro. Sendo assim este foi tido como um ponto negativo do setor, a ausência de uma brinquedoteca no próprio setor oncopediátrico, especifica para os pacientes.

Em relação aos pontos positivos no algoritmo da assistência a as crianças que estavam admitidas no HUAC no setor referido, foi relevante trabalhar a assistência com a atividade lúdica em sua forma de cuidado, pois contribuiu para minimizar os eventos desgastantes do processo de internação tais como: a baixa autoestima, a angústia, o sofrimento e a dor decorrente à hospitalização e os procedimentos que são realizados inerentes ao tratamento, destacando o procedimento de quimioterapia como sendo um momento em que a criança dispõe sua maior vulnerabilidade, devido às diversas reações que a ação dos fármacos causa no organismo.

Por meio das atividades lúdicas as crianças puderam expressar seus sentimentos e manifestar os eventos desagradáveis que ocorrem durante a internação, o brincar proporcionou a distração das crianças, maior interação entre elas, a adoção das estratégias lúdicas favoreceu também a interação entre a equipe e as crianças, como também entre a equipe e o acompanhante, geralmente as mães dos pacientes, promovendo assim uma relação de empatia, um ambiente mais acolhedor e descontraído para os enfermos.

Rebuscando a literatura os autores Simões et al 2010, destaca a importância do lúdico realizado nos hospitais que trabalham com crianças oncológicas e reafirma uma assistência embasada nos valores humanos, um assistência que também permita que o enfermo expresse seus sentimentos e o manifeste por meio de brincadeiras e que esse momento de recreação auxilie na elaboração de sentimentos que promovem o bem estar dos pacientes, o autor ainda diz que essas atividades promovam interação entre os enfermos e isso pode proporcionar uma saída do isolamento que a hospitalização causa.

No período de estágio foi visto essa interação com as crianças internadas, o vínculo entre um paciente e outro e as atividades tidas como recreativas demonstravam esse momento onde as crianças compartilhavam seus brinquedos, pintavam desenhos e trocavam ideias sobre jogos, participavam juntas de brincadeiras realizadas dentro da própria enfermaria.

Portanto, diante desta aceitação e satisfação das crianças que se divertem com as atividades realizadas, percebe-se que os pontos positivos se sobrepõem aos poucos pontos negativos, essa evidência reforça que 
este tipo de atividade compõe uma estratégia benéfica, e que deve ser implementada nos serviços independente da doença/limitação que o paciente dispor.

As atividades lúdicas eram realizadas geralmente todos os dias, porém estas ficavam na "responsabilidade" de voluntários que frequentavam o hospital. Contudo, sempre que possível à equipe de enfermagem também realizava atividades lúdicas, isso devido à rotina de local, a grande demanda de serviço ali existente, desde preparação de medicamentos, punção de cateter, administração da quimioterapia, burocracias, entre outras funções, tornando-se pequeno o espaço de tempo.

Nós acadêmicas realizávamos nossas atividades no setor que eram repassadas pelo profissional de plantão, como: a administração de quimioterápicos, as burocracias, administração de medicamentos entre outras funções cabíveis a enfermagem como também procurávamos sempre realizar brincadeiras e outras atividades de descontração com as crianças e seus familiares e essa era a melhor hora, pois ali arrancávamos sorrisos, atenção e alegria, podendo assim minimizar o sofrimento das crianças e seus familiares, melhorando a qualidade de vida destas.

\section{CONSIDERAÇÕES FINAIS}

Desta forma, percebemos que um ambiente hospitalar proporciona a criança sentimentos de medo e repercussões negativas, interferindo no desenvolvimento físico, psicológico e social. Além de tornar a hospitalização para a criança um evento estressante e traumatizante.

Os cuidados oferecidos pela enfermagem à criança com câncer são abrangentes e complexos. O profissional deve conhecer sobre a patologia, as técnicas precisas, e, sobretudo, oferecer apoio psicológico a criança e a família. Mas, frequentemente, com o intuito de atender a demanda e todas as necessidades biológicas, a atenção voltada para o apoio psicológico e social fica diminuído, ou até mesmo extinto.

A enfermagem tem como recurso de intervenção o brinquedo, o brincar. Para a criança é muito importante brincar, e a equipe de saúde deve reconhecer essa necessidade, fazendo com que esta ação seja inserida de forma sistemática no cuidado oferecido a criança internada diariamente.

Em relação ao Hospital Universitário Alcides Carneiro - HUAC, sabemos que existem problemas estruturais que dificultam o deslocamento da criança, da enfermaria a brinquedoteca, para a realização das atividades lúdicas, porém estes problemas não 
podem tornar-se empecilhos para a efetivação destas atividades.

O brincar beneficia as crianças, tornando-as mais receptivas aos serviços de saúde, aos procedimentos que serão realizados e principalmente a quimioterapia, adquirem uma confiança maior com os profissionais de saúde, diminuição do estresse, amenizando, assim, o sofrimento frente ao quadro clínico vivenciado.

\section{REFERÊNCIAS:}

AVANCI, B. S. Et al. Cuidados paliativos à criança oncológica na situação do viver/morrer: a ótica do cuidar em enfermagem. Esc. Anna Nery. Rio de Janeiro, v. 13, n. 4, 2009. Disponível em: $<$ http://www.scielo.br/scielo.php?script=sci_a rttext\&pid=S141481452009000400004\&lng= en\&nrm=iso $>$ Acesso em 03 Fevereiro 2014.

\section{BRASIL. Lei $n^{0} 11.104$, de 21 de março de}

2005. Dispõe sobre a obrigatoriedade de instalação de brinquedotecas nas unidades de saúde que ofereçam atendimento pediátrico em regime de internação. Brasília (DF):

Câmara dos Deputados; 2005. Disponível em: $<$ http://bvsms.saude.gov.br/bvs/saudelegis/gm ../2005/prt2261_23_11_2005.html> Acesso em 02 Fevereiro 2014.

CAGNIN, E. R. G.; Et. al.. Representação social da criança sobre o câncer. Rev. esc. enferm. USP. São Paulo, v. 38, n. 1, Mar. 2004 . Disponível em:
$<$ http://www.scielo.br/scielo.php?script=sci_a rttext\&pid=S008062342004000100007\&lng= en\&nrm=iso $>$ Acesso em 03 Fevereiro 2014.

CAIRES, S. et al. Vantagens da presença dos doutores palhaços no contexto hospitalar: as expectativas dos profissionais de pediatria.

Indagatio Didactica, v: 5, n: 2. 2013.

Disponível em: $<$ http://revistas.ua.pt/index.php/ID/article/vie w/2492/2360> Acesso em 07 Fevereiro 2014.

CARDOSO, F. T. Câncer Infantil: Aspectos Emocionais e Atuação do Psicólogo. Rev. SBPH v.10 n.1 Rio de Janeiro 2007.

Disponível em: $<$ http://pepsic.bvsalud.org/scielo.php?pid=S1 $51608582007000100004 \&$ script $=$ sci_arttext $>$ Acesso em 31 de janeiro de 2014.

\section{CONSELHO FEDERAL DE}

ENFERMAGEM (BR). Resolução COFEN

no 295, de 24 de outubro de 2004: dispõe

sobre a utilização da técnica do

Brinquedo/Brinquedo Terapêutico pelo

Enfermeiro na assistência à criança

hospitalizada. Brasília (DF); 2004. Disponível em:

<http://site.portalcofen.gov.br/node/4331>

Acesso em 02 Fevereiro 2014.

\section{HORTA WA. Processo De Enfermagem.}

São Paulo (SP): EPU; 1979.

Instituto Nacional de Câncer José Alencar

Gomes da Silva. Estimativa 2014: Incidência

de Câncer no Brasil. Rio de Janeiro: INCA, 
2014. Disponível em:

$<$ http://www.inca.gov.br/estimativa/2014/esti

mativa-24012014.pdf> Acesso em 07 de

fevereiro de 2014.

MOURA C.C; RESCK Z.M.R; DÁZIO

E.M.R Atividades lúdicas realizadas com pacientes portadores de neoplasia internados em um hospital geral. Rev. Rene.13(3):667-

76, 2012. Disponivel em:

$<$ http://www.revistarene.ufc.br/revista/index.p hp/revista/article/viewFile/734/pdf> Acesso em: 05 Fevereiro 2014.

MINAYO, C. de S. (org.). Pesquisa social: teoria, método e criatividade. $26^{\mathrm{a}} \mathrm{ed}$.

Petrópolis: Vozes, 2007.

PEDREIRA, J.L; PALANCA, I.

Psicooncologia pediátrica. 2007. Disponível em:

$<$ http://www.psicooncologia.org/profesionale s.php> Acesso em 31 Janeiro 2014.

\section{RIBEIRO, A. A. A importância do brincar}

no tratamento de criança com câncer hospitalizadas: uma revisão de literatura.

Pós- graduação. 2013. Disponível em:

$<$ http://bibliotecaatualiza.com.br/arquivotcc/E

ON/EON02/RIBEIRO-aline-alves.pdf>

Acesso em 07 Fevereiro 2014.

SIMÕES A A, Et. al. Satisfação de clientes hospitalizados em relação às atividades lúdicas desenvolvidas por estudantes universitários. Rev. Eletr. Enferm. p.107112, 2010. Disponível em:
$<$ http://www.fen.ufg.br/revista/v12/n1/v12n1a 13.htm> Acesso em11-Fev-2014.

SOUZA, G. K. O.; MARTINS, M. M. B. A

Brinquedoteca Hospitalar e a Recuperação de Crianças Internadas: uma Revisão

Bibliográfica. Saúde e Pesquisa, v. 6, n. 1, 2013. Disponível em:

$<$ http://cesumar.br/pesquisa/periodicos/index. php/saudpesq/article/view/2430/1854> Acesso em 02 Fevereiro 2014. 